\title{
The c-Jun N-Terminal Protein Kinase Signaling Pathway Mediates Bax Activation and Subsequent Neuronal Apoptosis through Interaction with Bim after Transient Focal Cerebral Ischemia
}

\author{
Shuzo Okuno, Atsushi Saito, Takeshi Hayashi, and Pak H. Chan \\ Department of Neurosurgery, Department of Neurology and Neurological Sciences, and Program in Neurosciences, Stanford University School of Medicine, \\ Stanford, California 94305-5487
}

\begin{abstract}
The c-Jun N-terminal protein kinase (JNK) signaling pathway is implicated in neuronal apoptosis. The mechanism by which activated JNK induces neuronal apoptosis is strongly linked to mitochondrial apoptogenic proteins, although the molecular machinery downstream of JNK has not been precisely elucidated. Our study examined the relevance of proapoptotic Bcl-2 family members in JNKmediated apoptosis after transient focal cerebral ischemia ( $\mathrm{tFCI}$ ), which, when induced by 60 min of middle cerebral artery (MCA) occlusion, elevated levels of JNK activity and phospho-JNK in the MCA territory. Phospho-JNK was primarily expressed in neurons and colocalized with terminal deoxynucleotidyl transferase-mediated biotinylated UTP nick end labeling (TUNEL)-positive cells. Inhibition of JNK activity by anthra[1,9-cd] pyrazol-6(2H)-one (SP600125), a selective JNK inhibitor, protected neurons from ischemia-induced apoptosis detected by TUNEL staining and an apoptotic-related DNA fragmentation assay. SP600125 blocked translocation of the cell death effector Bax from the cytosol to the mitochondria after tFCI. BimL (Bim long) was induced and phosphorylated parallel to JNK activity. Coimmunoprecipitation studies consistently revealed increased interaction of JNK with BimL, as well as BimL with Bax, after tFCI. SP600125 blocked these interactions at a dose that significantly inhibited JNK-induced neuronal apoptosis. These results suggest that the JNK signaling pathway is involved in ischemia-induced neuronal apoptosis by stimulation, at least in part, of Bax translocation to the mitochondria, in which BimL is likely regulated by JNK as a downstream substrate for transmission of apoptotic signals to Bax.
\end{abstract}

Key words: cerebral ischemia; apoptosis; c-Jun N-terminal kinase; SP600125; Bim; Bax

\section{Introduction}

Cerebral ischemia is implicated in neuronal apoptosis (Chan et al., 1998; Fujimura et al., 1999; Graham and Chen, 2001). The c-Jun N-terminal protein kinase (JNK) signaling pathway is a potential cascade mediating neuronal apoptosis triggered by focal and global ischemia (Irving and Bamford, 2002). However, it is unclear whether inhibition of JNK activation is beneficial for attenuating neuronal apoptosis after in vivo cerebral ischemia or how JNK signaling is mediated and transmitted to downstream apoptogenic molecules. To address these questions, we investigated the efficacy of anthra [1,9-cd] pyrazol-6(2H)-one (SP600125), a selective JNK inhibitor, against apoptotic DNA damage after transient focal cerebral ischemia ( $\mathrm{tFCI}$ ) and examined the role of pro-

Received Jan. 8, 2004; revised June 28, 2004; accepted June 28, 2004

This work was supported by National Institutes of Health Grants P50 NS14543, R01 NS25372, R01 NS36147, and R01 NS38653 and by an American Heart Association Bugher Foundation award. P.H.C. is a recipient of the Jacobs Javits Neuroscience Investigator award. We thank Cheryl Christensen for editorial assistance and Elizabeth Hoyte for figure preparation.

Correspondence should be addressed to Dr. Pak H. Chan, Neurosurgical Laboratories, Stanford University, 1201 Welch Road, MSLS \#P304, Stanford, CA 94305-5487. E-mail: phchan@stanford.edu.

DOI:10.1523/JNEUROSCI.1745-04.2004

Copyright $\odot 2004$ Society for Neuroscience $\quad$ 0270-6474/04/247879-09\$15.00/0 apoptotic Bcl-2 family members in JNK-mediated ischemic neuronal apoptosis.

Several mitochondrial proapoptotic molecules are involved in neuronal apoptosis in experimental ischemia, including cytochrome $c$, second mitochondria-derived activator of caspase (Smac), caspases, and Bax (Krajewski et al., 1995; Sugawara et al., 1999; Saito et al., 2003). However, there is little understanding of the signaling pathways upstream of the mitochondrial apoptotic machinery engaged in neuronal ischemia. There is strong evidence that JNK may be a key mediator for transmission of apoptotic signals to mitochondrial apoptosis-related proteins (Tournier et al., 2000; Lei et al., 2002; Chauhan et al., 2003). JNK has been shown to have a significant association with Bax and Bak, members of the BH1-3 multidomain Bcl-2 family, in the mediation of apoptosis and related cytochrome $c$ release after ultraviolet radiation. Bax is a potent regulator of mitochondriadependent apoptosis in a variety of stress conditions. Recent evidence implies that BH3-only proteins (e.g., Bad, Bim, HRK, and Bid) are essential for Bax and Bak activation. Bim targets the $\mathrm{BH} 3$ domain of Bax, causing its conformational change, which leads to its oligomerization and integration into the outer mitochondrial membrane, and the formation of channels for release of cytochrome $c$ and other mitochondrial apoptogenic factors 
(Donovan et al., 2002), which in turn lead to apoptosis. Based on these findings, we hypothesized that Bim may be a direct substrate of JNK in neuronal apoptosis after $\mathrm{tFCI}$, thereby transducing stress signals to Bax and Bak.

Of the three major isoforms of Bim [BimS (Bim short), BimL (Bim long), and BimEL (Bim extra long)] (O'Reilly et al., 2000), BimL and BimEL are induced and potentiated by JNK at both the transcriptional and posttranslational levels (Harris and Johnson, 2001; Puthalakath and Strasser, 2002; Lei and Davis, 2003; Putcha et al., 2003). The transcriptional mechanism by which Bim is induced via JNK activation remains to be determined. Posttranslationally, JNK promotes the dissociation of Bim from the dynein motor complex, thus promoting its proapoptotic activity (Lei and Davis, 2003). Alternatively, Bim can also undergo regulation by JNK phosphorylation, which enhances its cytotoxicity in cultured neurons (Putcha et al., 2003). These findings suggest that, during ischemic insult, JNK may preferentially involve Bim as a downstream substrate, transducing the proximal apoptotic signals to Bax. To test this hypothesis, we examined the regulatory role of JNK in Bim activity and its interaction with Bax after tFCI in the presence and absence of SP600125.

\section{Materials and Methods}

Focal cerebral ischemia. All of the procedures were in accordance with the National Institutes of Health Guide for the Care and Use of Laboratory Animals and were approved by the Administrative Panel on Laboratory Animal Care of Stanford University. Adult male Sprague Dawley rats (270-290 gm) were subjected to transient focal ischemia by intraluminal middle cerebral artery (MCA) blockade with a nylon suture, as described previously (Fujimura et al., 1998). The rats were anesthetized with $2.0 \%$ isoflurane in $30 \%$ oxygen and $70 \%$ nitrous oxide using a face mask. The rectal temperature was controlled at $37.0 \pm 0.5^{\circ} \mathrm{C}$ during surgery with a feedback-regulated heating pad. After a midline skin incision, the left external carotid artery was exposed, and its branches were electrocoagulated. A $22.0 \mathrm{~mm}$ 3-0 surgical monofilament nylon suture, blunted at the end, was introduced into the left internal carotid artery through the external carotid artery stump. After $60 \mathrm{~min}$ of MCA occlusion, blood flow was restored by the withdrawal of the nylon suture.

Drug injection. To investigate the role of the JNK pathway after focal cerebral ischemia, a specific JNK inhibitor was injected. The inhibitor, SP600125, was purchased from Biomol Research Laboratories (Plymouth Meeting, PA) and dissolved in dimethylsulfoxide and PBS. The scalp was incised on the midline, and the skull was exposed. SP600125 $(0.25,0.5$, or $1.0 \mathrm{mg} / \mathrm{kg}$ in $25 \%$ dimethylsulfoxide in PBS $)$ and the vehicle (25\% dimethylsulfoxide in PBS) were injected intracerebroventricularly ( $8 \mu$ l, bregma; $1.4 \mathrm{~mm}$ lateral, $0.8 \mathrm{~mm}$ posterior, $3.6 \mathrm{~mm}$ deep) $30 \mathrm{~min}$ before MCA occlusion.

Immunohistochemistry. Anesthetized animals, as well as normal controls ( $n=4$ each), were perfused with $10 \mathrm{U} / \mathrm{ml}$ heparin and subsequently with $4 \%$ paraformaldehyde in $0.1 \mathrm{~m}$ PBS, $\mathrm{pH} 7.4$, at $3,6,12$, and $24 \mathrm{hr}$ of reperfusion. The brains were removed, postfixed for $12 \mathrm{hr}$, sectioned at $50 \mu \mathrm{m}$ with a vibratome, and processed for immunohistochemistry. The sections were incubated with blocking solution and reacted with an antiphospho-JNK antibody and an anti-BimL antibody at dilutions of 1:250 and 1:1000, respectively. Immunohistochemistry was performed via the avidin-biotin technique, and then the nuclei were counterstained with methyl green solution for $10 \mathrm{~min}$.

Terminal deoxynucleotidyl transferase-mediated biotinylated UTP nick end labeling. To clarify the spatial distribution of DNA fragmentation, we performed terminal deoxynucleotidyl transferase-mediated biotinylated UTP nick end labeling (TUNEL) ( $n=4$ each). The sections fixed by $4 \%$ paraformaldehyde were prepared as described above and were incubated with NeuroPore (Trevigen, Gaithersburg, MD) for $30 \mathrm{~min}$. They were placed in $1 \times$ terminal deoxynucleotidyl transferase (TdT) buffer (Invitrogen, Carlsbad, CA) for $30 \mathrm{~min}$, followed by reaction with a TdT enzyme (Invitrogen) and biotinylated 16-deoxy-UTP (16-dUTP) (Roche Diagnostics, Indianapolis, IN) at $37^{\circ} \mathrm{C}$ for $90 \mathrm{~min}$. The sections were washed two times in SSC (150 mm sodium chloride, $15 \mathrm{~mm}$ sodium citrate, $\mathrm{pH}$ 7.4) for $15 \mathrm{~min}$, followed by washing in PBS two times for 15 $\mathrm{min}$. The avidin-biotin technique was applied, and then the nuclei were counterstained with methyl green solution for $10 \mathrm{~min}$.

Immunofluorescent double-labeling staining. To evaluate colocalization of phospho-JNK, BimL, and neuron-specific nuclear protein (NeuN), we performed double immunofluorescent staining $(n=4$ each). The sections fixed by $4 \%$ paraformaldehyde were immunostained with the antiphospho-JNK or anti-BimL antibodies as described above, with biotinylated goat anti-mouse or anti-rat IgG (Vector Laboratories, Burlingame, $\mathrm{CA})$, followed by fluorescein avidin DCS (Vector Laboratories). Then the sections were reacted with an anti-NeuN or an anti-BimL antibody, followed by Texas Red-conjugated horse anti-mouse or goat anti-rat IgG antibody (Vector Laboratories) at a dilution of 1:200. The sections were placed on slides, which were then covered with Vectashield mounting medium with 4',6 diamidino-2-phenylindole (Vector Laboratories). Fluorescence of fluorescein was observed at excitation of $495 \mathrm{~nm}$ and emission of $>515 \mathrm{~nm}$, and fluorescence of Texas Red was observed at excitation of $510 \mathrm{~nm}$ and emission of $>580 \mathrm{~nm}$. Fluorescence of $4^{\prime}, 6$ diamidino-2-phenylindole was observed at excitation of $360 \mathrm{~nm}$ and emission of $>460 \mathrm{~nm}$.

Immunofluorescent double labeling with phospho-JNK immunohistochemistry and TUNEL. To clarify the spatial relationship between phospho-JNK expression and DNA fragmentation, we performed double staining for phospho-JNK and TUNEL, using a fluorescent method $(n=4$ each). The sections fixed by $4 \%$ paraformaldehyde were immunostained with the phospho-JNK antibody as described above, with biotinylated goat anti-mouse IgG (Vector Laboratories), followed by fluorescein avidin DCS (Vector Laboratories). Then the sections were incubated with NeuroPore (Trevigen) for $30 \mathrm{~min}$ and placed in $1 \times \mathrm{TdT}$ buffer (Invitrogen) for $30 \mathrm{~min}$, followed by reaction with TdT enzyme (Invitrogen) and biotinylated 16-dUTP (Roche Diagnostics) at $37^{\circ} \mathrm{C}$ for $90 \mathrm{~min}$. The sections were washed two times in SSC (150 mM sodium chloride, $15 \mathrm{~mm}$ sodium citrate, $\mathrm{pH}$ 7.4) for $15 \mathrm{~min}$, followed by washing in PBS two times for $15 \mathrm{~min}$. Texas Red avidin DCS (Vector Laboratories) was applied to the sections for $30 \mathrm{~min}$. Subsequently, the slides were covered with Vectashield mounting medium with 4',6 diamidino-2phenylindole (Vector Laboratories). Fluorescence was assessed as described above.

Western blot analysis. Whole-cell protein extraction was performed. Samples were obtained from the entire MCA territory on the ischemic side and from the nonischemic controls ( $n=6$ each). Fresh brain tissue was cut into pieces after $3,6,12$, and $24 \mathrm{hr}$ of reperfusion and homogenized in 7 vol of cold suspension buffer (20 mM HEPES-KOH, pH 7.5, $250 \mathrm{~mm}$ sucrose, $10 \mathrm{~mm} \mathrm{KCl}, 1.5 \mathrm{~mm} \mathrm{MgCl}_{2}, 1 \mathrm{~mm}$ EDTA, 1 mм EGTA, $0.7 \%$ protease, and phosphatase inhibitor mixtures) (Sigma, St. Louis, MO). To obtain the whole-cell lysates, the tissue was homogenized and centrifuged at $10,000 \times \mathrm{g}$ for $20 \mathrm{~min}$ at $4^{\circ} \mathrm{C}$, and the supernatant was used for the analysis. After the same volume of Tris-glycine SDS sample buffer (Invitrogen) was added to the supernatant, equal amounts of the samples were loaded per lane. For subcellular fractionation, lysates were made with a glass tissue grinder (Wheaton, Millville, NJ). The lysates were centrifuged at $750 \times g$ for $10 \mathrm{~min}$ at $4^{\circ} \mathrm{C}$ and then at $8000 \times g$ for $20 \mathrm{~min}$ at $4^{\circ} \mathrm{C}$. The $8000 \times g$ pellets were used to obtain the mitochondrial fraction. The supernatant was centrifuged further at $100,000 \times g$ for 60 $\min$ at $4^{\circ} \mathrm{C}$. This supernatant was used for the cytosolic analysis. Proteins were separated on $10-20 \%$ SDS polyacrylamide gels and electrophoretically transferred to polyvinylidene difluoride membranes, which were then incubated overnight at $4^{\circ} \mathrm{C}$ with the primary antibody diluted in blocking solution. After washing, membranes were treated with horseradish peroxidase-conjugated secondary antibodies and then with enhanced chemiluminescence reagent (Amersham Biosciences, Piscataway, NJ). Western blots were performed with horseradish peroxidaseconjugated anti-rabbit IgG (Cell Signaling Technology, Beverly, MA) or anti-mouse IgG (Chemicon International, Temecula, CA) using enhanced chemiluminescence Western blotting detection reagents (Amersham Biosciences). The film was scanned with a GS-700 imaging densitometer (Bio-Rad Laboratories, Hercules, CA), and the results were quantified with Multi-Analyst software (Bio-Rad Laboratories). 
Antibodies. The following antibodies were used for Western blot analysis: mouse monoclonal anti-phospho-JNK $\left(\mathrm{Thr}^{183} / \mathrm{Tyr}^{185}\right)$, rabbit polyclonal anti-JNK, phospho-SEK1 (stress-activated protein kinase/extracellular signal-regulated kinase-1)/MKK4 (mitogen-activated protein kinase kinase 4) ( $\mathrm{Thr}^{261}$ ), phospho-c-Jun $\left(\mathrm{Ser}^{63}\right)$ (all from Cell Signaling Technology), rat monoclonal anti-BimL (Chemicon International), rat monoclonal anti-dynein light chain 1 (DLC1) (Kamiya Biomedical, Seattle, WA), mouse monoclonal anti-Bax (Santa Cruz Biotechnology, Santa Cruz, CA), mouse monoclonal anti- $\beta$-actin (Sigma), and mouse monoclonal anticytochrome oxidase IV (Molecular Probes, Eugene, OR).

The following antibodies were used for coimmunoprecipitation: rabbit polyclonal anti-JNK (Cell Signaling Technology), rat monoclonal anti-BimL, mouse monoclonal anti-dynein intermediate chain (DI) (Chemicon International), and mouse monoclonal anti-Bax (Santa Cruz Biotechnology).

The following antibodies were used for immunohistochemistry and immunofluorescent staining: mouse monoclonal anti-phospho-JNK $\left(\mathrm{Thr}^{183} / \mathrm{Tyr}^{185}\right.$ ), phospho-c-Jun $\left(\mathrm{Ser}^{63}\right.$ ) (all from Cell Signaling Technology), rat monoclonal anti-BimL, and mouse monoclonal anti-NeuN (Chemicon International).

Coimmunoprecipitation. The procedure for precipitation was performed as described previously with some modification (Springer et al., 2000). Samples were obtained from the MCA territory brain tissue on the ischemic side and from nonischemic controls ( $n=4$ each). Fresh brain tissue was removed after $3,6,12$, and $24 \mathrm{hr}$ ( $n=4$ each) of reperfusion. Protein concentrations were determined by the Bradford method (BioRad Laboratories). Three hundred micrograms of protein were used for coimmunoprecipitation. The protein sample was incubated with $50 \%$ slurry of protein A- or G-Sepharose (Amersham Biosciences) for $4 \mathrm{hr}$ at $4^{\circ} \mathrm{C}$, and this mixed sample was centrifuged at $12,000 \times g$ for $1 \mathrm{~min}$. The supernatant was incubated with $2-5 \mu \mathrm{g}$ of antibodies and $20 \mu \mathrm{l}$ of protein A- or G-Sepharose ( $50 \%$ slurry) at $4^{\circ} \mathrm{C}$ overnight. The negative control was prepared with protein A- or G-Sepharose without antibody. The $14,000 \times g$ pellets were washed four times. After adding the same volume of Tris-glycine SDS sample buffer (Invitrogen) to the sample, we boiled these samples to remove Sepharose beads. After centrifugation at $14,000 \times g$ for $1 \mathrm{~min}$, the supernatant was immunoblotted as described in the Western blot analysis.

Mitogen-activated protein kinases and AKT activity. Mitogen-activated protein kinases (MAPKs) and AKT activity were measured with immune complex protein kinase assays according to the manufacturer's protocol (Cell Signaling Technology). Briefly, cells were lysed in ice-cold cell lysis buffer (20 mм Tris, pH 7.5, 150 mм NaCl, 1 mм EDTA, 1 mм EGTA, 1\% Triton X-100, $2.5 \mathrm{~mm}$ sodium pyrophosphate, $1 \mathrm{~mm}$ glycerol phosphate, $1 \mathrm{~mm} \mathrm{Na}_{3} \mathrm{VO}_{4}, 1 \mu \mathrm{g} / \mathrm{ml}$ leupeptin, and $1 \mathrm{~mm}$ phenylmethylsulfonyl fluoride). Equal volumes of cell lysates $(300 \mu \mathrm{g})$ were incubated with c-Jun fusion protein beads, immobilized phospho-p38 monoclonal antibody, immobilized phospho-extracellular signal-regulated kinase (ERK) monoclonal antibody, and immobilized AKT 1G1 monoclonal antibody for JNK, p38, ERK, and AKT, respectively, at $4^{\circ} \mathrm{C}$ overnight. After centrifugation, pellets were suspended by kinase buffer ( $25 \mathrm{~mm}$ Tris, $\mathrm{pH} 7.5$, $5 \mathrm{~mm}$ glycerol phosphate, $2 \mathrm{~mm}$ dithiothreitol, $0.1 \mathrm{mM} \mathrm{Na}_{3} \mathrm{VO}_{4}, 10 \mathrm{~mm}$ $\mathrm{MgCl}_{2}$, and $200 \mu \mathrm{M} \mathrm{ATP}$ ) and then immunoprecipitated with the specific fusion protein c-Jun, activating transcription factor-2, Elk-1, and GSK-3, for JNK, p38, ERK, and AKT, respectively, at $30^{\circ} \mathrm{C}$ for $30 \mathrm{~min}$. The activity of JNK, p38, ERK, and AKT was then measured by Western blot with a 1:1000 dilution of primary antibodies [rabbit polyclonal phosphoc-Jun $\left(\mathrm{Ser}^{63}\right)$, phospho-activating transcription factor-2 $\left(\mathrm{Thr}^{71}\right)$, phospho-Elk-1 (Ser $\left.{ }^{383}\right)$, and phospho-GSK-3 $\alpha / \beta$ (Ser $\left.{ }^{21 / 9}\right)$ antibodies] as described in the Western blot analysis.

Cell death assay. For quantification of apoptotic-related DNA fragmentation, we used a commercial enzyme immunoassay to determine cytoplasmic histone-associated DNA fragments (Roche Diagnostics). This assay detects apoptotic but not necrotic cell death. Samples were obtained from the entire MCA territory or the MCA territory cortex on the ischemic side and from nonischemic controls ( $n=4$ each). Fresh brain tissue was cut into pieces after $24 \mathrm{hr}$ of reperfusion, homogenized with a Teflon homogenizer in $5 \mathrm{vol}$ of ice-cold buffer (in mM: $50 \mathrm{KH}_{2} \mathrm{PO}_{4}$ and 0.1 EDTA, pH 7.8), and spun for $10 \mathrm{~min}$ at $750 \times \mathrm{g}$. The supernatant was collected and spun for $20 \mathrm{~min}$ at $10,000 \times g$, and then was further centrifuged at $100,000 \times g$ for $60 \mathrm{~min}$ at $4^{\circ} \mathrm{C}$. The resulting supernatant was collected, and the protein concentration was determined. A cytosolic volume containing $20 \mu \mathrm{g}$ of protein was used for the ELISA, according to the manufacturer's protocol.

Quantification and statistical analysis. The data are expressed as mean $\pm \mathrm{SD}$. Comparisons among multiple groups were performed by one-way ANOVA with appropriate post hoc tests (SigmaStat software; Jandel, San Rafael, CA). Significance was accepted with $p<0.05$.

\section{Results}

\section{The JNK signaling pathway was activated in neurons after} tFCI and was related to apoptosis

To confirm that the JNK signaling pathway could be activated in the brain subjected to transient ischemia (Fig. $1 \mathrm{~A}$ ), we first examined JNK activity by immunocomplex assay and JNK phosphorylation by Western blot analysis. The level of JNK activity was significantly increased 2.4- and 6.7-fold 3 and $6 \mathrm{hr}$ after reperfusion, respectively, compared with the nonischemic controls (Fig. 1 B). The time course of phospho-JNK $\left(\mathrm{Thr}^{183} / \mathrm{Tyr}^{185}\right.$ ) expression had the same profile as that of JNK activity, peaking at $6 \mathrm{hr}$. Two bands with molecular masses of $46 \mathrm{kDa}$ (JNK1) and 54 $\mathrm{kDa}(\mathrm{JNK} 2 / 3)$ in the whole-cell fraction from the MCA territory brain tissue were evident. There was no change in total JNK protein expression after reperfusion in the ischemic brains. We also investigated whether activation of MKK4, one of the upstream kinases of JNK, had been altered in the ischemic brain. The appearance of phospho-MKK4 $\left(\mathrm{Thr}^{261}\right)$ was almost parallel to that of JNK activity and peaked at $6 \mathrm{hr}$. In contrast, no increase in levels of phospho-c-Jun $\left(\mathrm{Ser}^{63}\right)$ was detected during reperfusion. As shown in Figure $1 C$, immunohistochemistry demonstrated that phospho-JNK expression was increased after $6 \mathrm{hr}$ of reperfusion in the caudate-putamen, but gradually decreased by $24 \mathrm{hr}$. In the MCA territory cortex, however, we detected less of an increase in phospho-JNK immunoreactivity. Immunostaining without a primary antibody against phospho-JNK showed no immunoreactivity (data not shown). Immunohistochemistry for phospho-c-Jun $\left(\mathrm{Ser}^{63}\right.$ ) was not evident in the entire ischemic MCA territory for the duration of the experiment (data not shown). Double immunofluorescent staining for phospho-JNK and NeuN indicated that phospho-JNK-positive cells in the ischemic core colocalized primarily with neurons. Phospho-JNK staining was present primarily in the cytoplasm of neurons. There was no apparent redistribution of the phospho-JNK protein to nuclei (Fig. 1D). There was no immunostaining when the antiphospho-JNK antibody was omitted (data not shown). After 24 hr of reperfusion, a significant number of TUNEL-positive cells was detected in the caudate-putamen with shrunken, condensed nuclei and apoptotic bodies. Most phospho-JNK immunoreactivity colocalized with TUNEL-positive cells, but some TUNELpositive cells colocalized with phospho-JNK immunoreactivity (Fig. $1 E$ ). These findings suggest that the JNK signaling pathway was activated in neurons after tFCI and that activated JNK is likely related to the molecular machinery preceding apoptotic cell death induced by tFCI.

\section{Selective inhibition of JNK activity by SP600125 attenuated Bax translocation and subsequent apoptosis in} ischemic neurons

A previous report showed that SP600125 is a highly selective inhibitor of JNK1, -2, and -3 (Bennett et al., 2001). To identify the selectivity of SP600125 in inhibition of JNK activity, we examined kinase assays for JNK, p38, ERK1/2, and AKT at different drug concentrations. SP600125 significantly inhibited ischemia- 
A

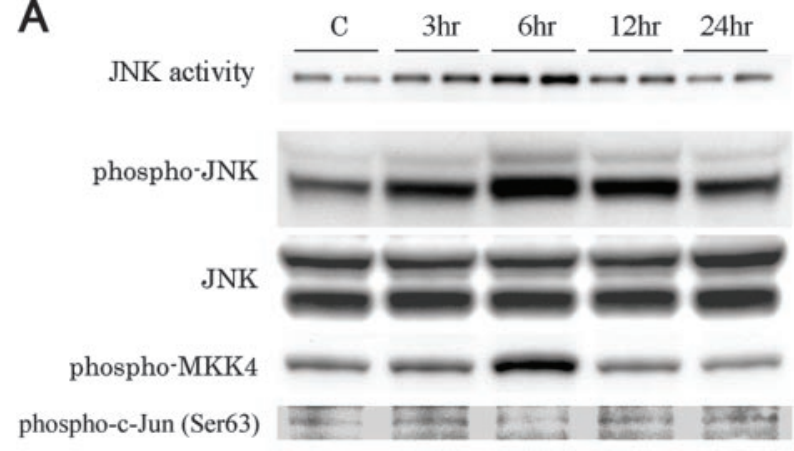

B
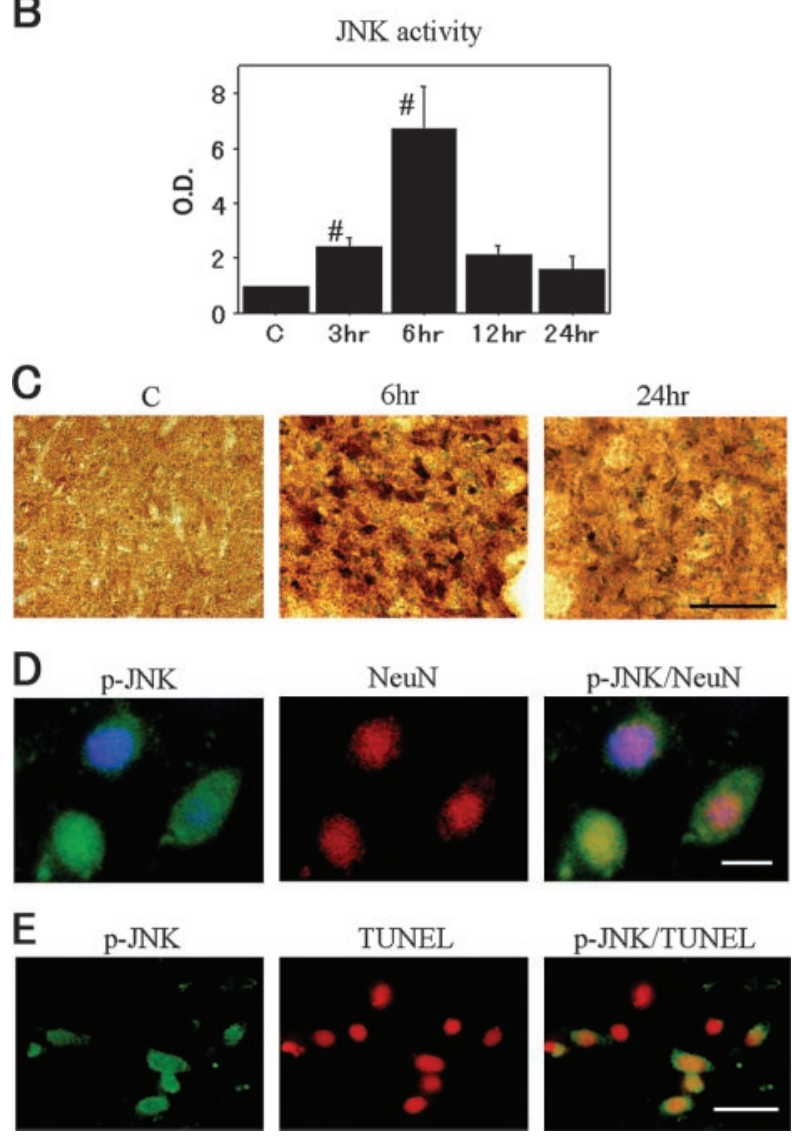

Figure 1. A, JNK activity assay and Western blot analyses of phospho-JNK, JNK, phosphoMKK4, and phospho-c-Jun (Ser ${ }^{63}$ ) in the whole-cell fraction from the MCA territory in rat brains. JNK activity was significantly increased at $6 \mathrm{hr}$ compared with the nonischemic control brains (lane (). The phospho-JNK bands were observed at 46 and $54 \mathrm{kDa}$ and increased parallel to JNK activity. JNK expression was not increased or decreased after reperfusion. An increased level of phospho-MKK4 was shown at $6 \mathrm{hr}$, whereas no increase in phospho-c-Jun levels was detected during reperfusion. $B$, Quantitative analysis $(n=4)$ showed a significant increase in JNK activity $6 \mathrm{hr}$ after tFCl, compared with the healthy control (C) $\left.{ }^{\#} p<0.05\right)$. 0.D., Optical density. Error bars represent mean $\pm S D$. C, Representative photomicrographs show the immunohistochemistry for phospho-JNK in the caudate-putamen of the MCA territory after tFCl. After $6 \mathrm{hr}$ of reperfusion, phospho-JNK expression was intensely increased compared with the same region in the nonischemic rat brains. After $24 \mathrm{hr}$ of reperfusion, phospho-JNK immunoreactivity became weak but was still clearly observed in a considerable number of cells. Scale bar, $50 \mu \mathrm{m}$. D, Representative photomicrographs show double immunofluorescent staining for phospho-JNK (p-JNK) and NeuN. Six hours after reperfusion, p-JNK-positive cells were observed in the ischemic caudate-putamen. NeuN immunoreactivity showed the distribution of neurons in the same view. Overlapped image of $\mathrm{p}$-JNK and NeuN immunoreactivity demonstrated p-JNK-positive cells colocalized primarily with neurons. Scale bar, $8 \mu \mathrm{m}$. E, Representative photomicrographs show double immunofluorescent staining for p-JNK and TUNEL $24 \mathrm{hr}$ after tFCl. In the ischemic caudateputamen, $p$-JNK-positive cells were observed. A significant number of TUNEL-positive cells was seen in the same area. Overlapped image of $p$-JNK and TUNEL demonstrated that some TUNEL-positive cells were colocalized with p-JNK-positive cells. Scale bar, $20 \mu \mathrm{m}$. induced JNK activity in a dose-dependent manner at $6 \mathrm{hr}$ of reperfusion (Fig. $2 A, B$ ), whereas kinase activity of p38, ERK1/2, or AKT was not affected in the presence of SP600125 (Fig. 2C). The levels of phospho-JNK and phospho-MKK4 were not altered by SP600125 treatment (Fig. 2C). This result may be attributable to the ATP-competitive nature of SP600125, which selectively inhibits kinase activity but not JNK phosphorylation or MKK4 (Bennett et al., 2001). We first determined whether Bax translocated from the cytosol to the mitochondria after tFCI. Using Western blot analysis and subcellular fractionation, we found that basal expression of Bax predominated in the cytosol and continued to decrease up to $24 \mathrm{hr}$ after reperfusion. Accordingly, mitochondrial Bax immunoreactivity increased (Fig. 2 D). Moreover, we examined whether the JNK signaling pathway contributes to Bax translocation. The inhibitory effect of SP600125 on Bax translocation in the mitochondrial fraction was not complete, but it reached a statistically significant difference $24 \mathrm{hr}$ after ischemia-reperfusion compared with the vehicle-treated animals (Fig. 2E). Next, we assessed apoptotic-related DNA fragmentation after $\mathrm{tFCI}$ with the use of a commercial cell death assay kit. As shown in Figure $2 F$, DNA fragmentation was significantly increased in the ischemic MCA territory $24 \mathrm{hr}$ after reperfusion compared with the nonischemic brain samples. Treatment at the highest dose of SP600125, which was injected into the ventricle, resulted in a significant decrease $(58 \%)$ in DNA fragmentation. TUNEL-positive cells were obvious in the caudate-putamen, but sparse in the ischemic cortex of the MCA territory at $24 \mathrm{hr}$. In the SP600125-treated animals, TUNEL reactivity decreased in both the caudate-putamen and the cortex compared with the vehicletreated animals (Fig. 2G). In contrast, an ischemic lesion detected by 2,3,5-triphenyltetrazolium chloride (TTC) staining $24 \mathrm{hr}$ after ischemia-reperfusion was not different between the vehicletreated and the SP600125-treated animals (data not shown). These findings suggest a proapoptotic role for JNK activity in brain tissue subjected to ischemia and its significant relevance to the regulation of Bax activation.

Bim was induced and phosphorylated in neurons during tFCI To confirm the involvement of Bim, a proapoptotic BH3-only protein, in the apoptotic program during ischemia-reperfusion injury, the whole-cell lysates were subjected to Western blot analysis. BimL immunoreactivity was evident with a molecular mass of $24 \mathrm{kDa}$. BimL expression was transiently and significantly induced in the ischemic brain on Western blot analysis, with a peak $6 \mathrm{hr}$ after reperfusion. In particular, the expression of slowermigrating bands was avidly upregulated (Fig. $3 A, B$ ). The kinetics of BimL expression was consistently parallel to that of JNK activation. To test whether the bands with decreased electrophoretic mobility indicated phosphorylated forms of BimL, we treated the animals with an intracerebroventricular injection of okadaic acid (10 or $100 \mathrm{ng} / \mathrm{kg}$ of body weight), an inhibitor of protein phosphatases 1 and 2A. Okadaic acid enhanced protein phosphorylation, resulting in increased expression of BimL proteins associated with reduced electrophoretic mobility (Fig. 3C). We cannot exclude the possibility that okadaic acid modifies unknown regulatory mechanisms for BimL because of its nonspecific nature in the enhancement of phosphorylation. Even so, these findings suggest BimL proteins are phosphorylated through ischemiainduced stress signaling. The temporospatial profile of BimL immunoreactivity was completely in agreement with that of phospho-JNK immunoreactivity when examined by immunohistochemistry (Fig. 3D) and double immunofluorescence with NeuN (Fig. 3E). In these histological studies, scant immunoreac- 
A

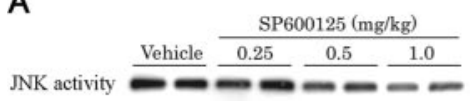

B

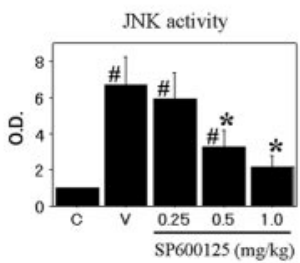

C

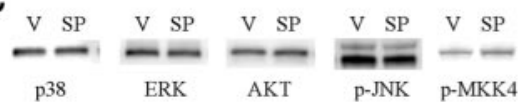

D
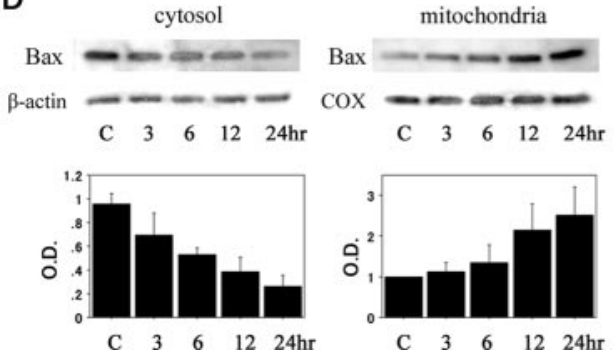

Figure 2. A, JNK activity assay of the whole-cell fraction in the SP600125-treated rats and the vehicle-treated rats $6 \mathrm{hr}$ after tFCl. JNK activity was decreased with SP600125 treatment in a dose-dependent manner. B, The inhibitory effect of SP600125 on JNK activity reached statistical significance at a dose of $0.5 \mathrm{mg} / \mathrm{kg}$ compared with the vehicle-treated $(\mathrm{V})$ animals $\left(n=4\right.$; $^{*} p<$ 0.05, compared with the vehicle-treated animals). In the SP600125-treated rats at a dose of $1.0 \mathrm{mg} / \mathrm{kg}$, JNK activity was not significantly changed compared with the nonischemic control brains $(C)\left(n=4 ;{ }^{\#} p<0.05\right.$, compared with the nonischemic control brains). C, The effect of SP600125 on different kinases $6 \mathrm{hr}$ after tFCI. Kinase assays showed that SP600125 caused no reduction in p38, ERK, or AKT activity. Phospho-JNK ( $p$-JNK) and phospho-MKK4 (p-MKK4) were expressed similarly in the absence or presence of SP600125 by Western blot analysis. SP, SP600125 $(1.0 \mathrm{mg} / \mathrm{kg})$. D, Bax was predominantly expressed in the cytosol of the nonischemic control brains (C). After the onset of ischemia-reperfusion, Bax was successively translocated to the mitochondria during the experiment. Quantitative analysis $(n=4)$ clearly showed a reciprocal expression of Bax between the cytosolic and mitochondrial fractions $24 \mathrm{hr}$ after reperfusion. COX, Cytochrome oxidase. E, Animals treated with the vehicle or SP600125 were subjected to $\mathrm{tFCl}$. Bax translocation in the mitochondrial fraction $24 \mathrm{hr}$ after reperfusion was significantly reduced with a 1.0 $\mathrm{mg} / \mathrm{kg}$ dose of SP600125 compared with the vehicle-treated animals $\left(n=4 ;{ }^{*} p<0.05\right)$. F, Apoptotic-related DNA fragmentation after $\mathrm{FCl}$ was analyzed with a commercial cell death detection kit $(n=4)$. DNA fragmentation increased significantly in the entire MCA territory lesion $24 \mathrm{hr}$ after reperfusion. In the SP600125-treated animals, DNA fragmentation significantly decreased at a dose of $1.0 \mathrm{mg} / \mathrm{kg}$ compared with the vehicle-treated (V) animals $24 \mathrm{hr}$ after tFCl ( ${ }^{*} p<0.05$ ). G, Representative photomicrographs show TUNEL-positive cells in the caudate-putamen of the vehicle-treated and SP600125-treated groups $24 \mathrm{hr}$ after tFCl. TUNEL-positive cells were strongly expressed in the vehicle-treated animals, whereas in the animals treated with SP600125 (1.0 $\mathrm{mg} / \mathrm{kg}$ ), TUNEL reactivity decreased. Error bars represent mean \pm SD. Scale bar, $30 \mu \mathrm{m}$.

tivity was present when we omitted the anti-BimL antibody (data not shown). Moreover, because Bim reportedly translocates to mitochondria and binds to Bcl-2-like proteins, thereby modulating apoptotic signals (Puthalakath et al., 1999), we examined the BimL protein to see whether its subcellular localization was altered after cerebral ischemia. As shown in Figure 3F, BimL localized to the cytosolic fraction under normal conditions and did not redistribute to mitochondria after tFCI. Lastly, to demonstrate the possible involvement of JNK in BimL regulation, we examined the effect of SP 600125 on BimL expression by Western blot analysis. Treatment with SP600125 caused a dose-dependent decrease in levels of phosphorylated BimL (Fig. 3G). Reduction in BimL expression reached statistical significance at a concentration of $1.0 \mathrm{mg} / \mathrm{kg}$ (Fig. $3 \mathrm{H}$ ). These results indicate that, during reperfusion in the ischemic brain, BimL is induced and phosphorylated primarily in the neuronal cytosol without changes to its subcellular localization and that BimL acts as a downstream component of the activated JNK signaling pathway after reperfusion.

\section{Ischemia-inducible binding activity of} Bim is dependent on JNK activity

To confirm an interaction between JNK and Bim, whole-cell lysates were coimmunoprecipitated with an anti-JNK antibody. The immunoreactivity of JNK-associated BimL was examined by Western blot analysis. There was a significant increase in the expression of BimL precipitated by JNK and associated proteins up to $6 \mathrm{hr}$ after reperfusion. Thereafter, the binding of JNK to BimL consistently decreased (Fig. $4 A$ ). This profile of kinetics in JNK-BimL interaction is consistent with that in JNK activation or phosphorylated BimL. Coimmunoprecipitation studies using subcellular fractions demonstrated that JNK immunoprecipitates from the cytosolic fraction, but not from the mitochondrial fraction, contained BimL on Western blot analysis (Fig. $4 B$ ). To examine the contribution of JNK activity to ischemiainduced JNK-BimL interaction, we performed studies using SP600125. The amount of BimL that coimmunoprecipitated with JNK significantly decreased after treatment with SP600125 in a dosedependent manner (Fig. 4C,D). Double immunofluorescence also showed that phospho-JNK colocalized with BimL (Fig. $4 E$ ). These data strongly suggest that BimL is involved in JNK-mediated neuronal apoptosis after tFCI as a direct substrate for JNK phosphorylation. Bim has been reported to require other members of the Bcl-2 family, like Bax or Bak, to exhibit its proapoptotic activity (Cheng et al., 2001; Zong et al., 2001). To determine whether BimL proteins are in a complex with Bax in the ischemic brain, BimL expression was analyzed in the absence or presence of SP600125 by Western blotting with wholecell lysates that were immunoprecipitated with an anti-Bax antibody. The binding of BimL to Bax clearly increased $6 \mathrm{hr}$ after reperfusion compared with the nonischemic controls. SP600125 treatment significantly antagonized BimL-Bax binding (Fig. $4 F$ ). These data show that JNK activity contributes to the direct binding of BimL to Bax. All of these data show that JNK preferentially involves Bim as a downstream mediator in the cytosol, by which stress signaling is transmitted to Bax, one of the mitochondrial apoptogenic molecules.

\section{Dissociation of Bim from the dynein motor complex during tFCI}

From recent studies, we know that BimL is sequestered by binding to the DLC1, a component of the microtubule-associated dynein motor complex in vitro. Certain stress conditions cause 
release of BimL alone or with DLC1 from the dynein motor complex, freeing BimL to induce apoptosis (Puthalakath et al., 1999). We first performed a Western blot analysis to investigate the expression of DLC1 after $\mathrm{tFCI}$, which was reduced at $6 \mathrm{hr}$ (Fig. 5A). However, SP600125 treatment did not alter the expression of DLC1 and DI (data not shown). We performed coimmunoprecipitation experiments to investigate whether the regulatory mechanism of BimL by DLC1 is involved in brain ischemia. After tFCI, the amount of DLC1 that was coimmunoprecipitated with BimL from the whole-cell lysates decreased at 6 hr (Fig. 5B). Next, we examined the binding properties between DLC1 and DI. Similarly, the dissociation of DLC1 from DI was shown $6 \mathrm{hr}$ after reperfusion (Fig. 5B). These data indicate that the dissociation of BimL from the dynein motor complex may possibly be involved in the regulatory mechanism of BimL during $\mathrm{tFCI}$ independent of the JNK signaling pathway.

\section{Discussion}

A number of studies have demonstrated activation of the JNK signaling pathway after global and focal cerebral ischemia, whereas the profile of activation differs greatly among reports (Irving and Bamford, 2002). This inconsistency appears to mostly depend on the balance between the vulnerability of ischemic tissue and the severity of hypoperfusion among the individual settings of the experiments. Studies of selective JNK inhibition by means of genetic or pharmacological methods are needed to confirm the distinct role of JNK in mediating ischemia-induced cell death in neurons. Major protection by a peptide inhibitor of JNK in necrotic lesions has been reported after focal cerebral ischemia in rodents (Borsello et al., 2003). Moreover, a critical role for JNK in the brain penumbra has been determined from JNK3-deficient mice subjected to ischemia-hypoxia stress (Levine's procedure) (Kuan et al., 2003). In the present studies, we demonstrated that JNK inactivation by SP600125, an ATP-competitive inhibitor, was potently effective in decreasing neuronal apoptosis in the ischemic core after in vivo tFCI. Increased activity as well as phosphorylation of the JNK protein was confirmed in the caudate-putamen but not in the MCA territory cortex of the marginal penumbra. In addition, we showed increased levels of phospho-MKK4 $\left(\mathrm{Thr}^{261}\right)$ after in vivo cerebral ischemia. JNK is activated by phosphorylation on $\mathrm{Thr}^{183}$ and $\mathrm{Tyr}^{185}$ by the upstream activators MKK4 and MKK7. These upstream kinases are, in turn, activated by the MAPKKK (mitogenactivated protein kinase kinase kinase) families, including the MLK (mixed lineage kinase) and MEKK (mitogen-activated protein/ERK kinase kinase) families (Davis, 2000). Our Western blot
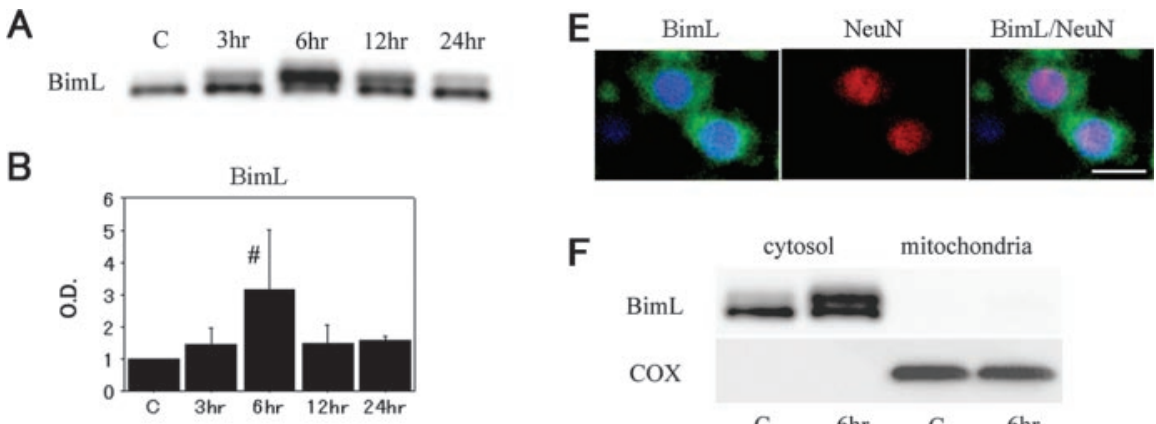

$\mathbf{F}$

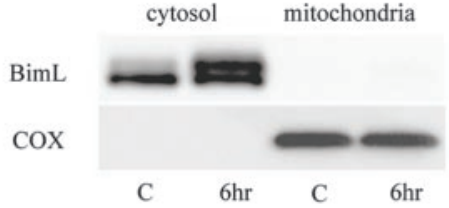

G
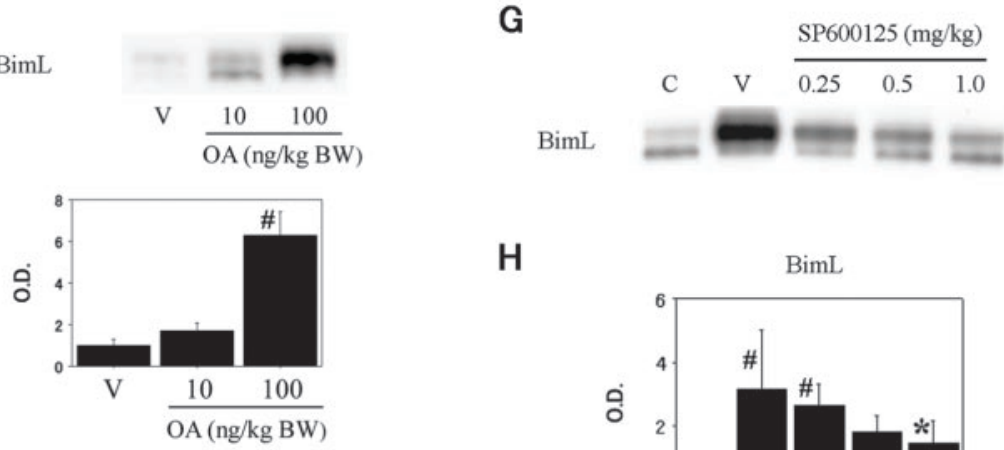

$\mathbf{H}$

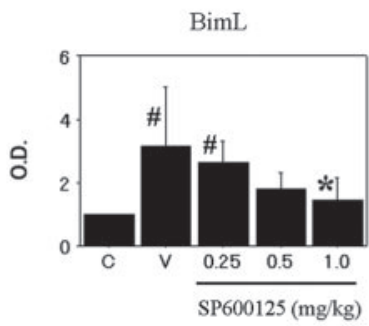

Figure 3. $A$, Western blot analysis of BimL in the MCA territory of rat brains after $\mathrm{EFCl}$. The band of BimL was evident at $24 \mathrm{kDa}$ and peaked $6 \mathrm{hr}$ after reperfusion. C, Control. B, Quantitative analysis $(n=4)$ showed a significant increase in BimL induction $6 \mathrm{hr}$ after $\mathrm{tFCl}$, compared with the healthy controls (C) ( $\left.{ }^{\#} p<0.05\right)$. 0.D., Optical density. C, Okadaic acid (OA) enhanced phosphorylation of BimL proteins. Intracerebroventricular injection of $O A(100 \mathrm{ng} / \mathrm{kg})$ was associated with a decrease in electrophoretic mobility of BimL expression ( $n=4 ; \# p<0.05$, compared with the vehicle-treated animals). BW, Body weight. D, Representative photomicrographs show immunohistochemistry for BimL in the caudate-putamen of the MCA territory after tFCI. After $6 \mathrm{hr}$ of reperfusion, BimL expression was intensely increased compared with the same region in the nonischemic rat brains (C). After 24 hr of reperfusion, BimL immunoreactivity became weak but was still clearly observed in a considerable number of cells. Scale bar, $50 \mu \mathrm{m}$. E, Representative photomicrographs show double immunofluorescent staining for BimL and NeuN. Six hours after reperfusion, BimL-positive cells were observed in the ischemic caudate-putamen. NeuN immunoreactivity showed the distribution of neurons in the same view. Overlapped image of BimL and NeuN immunoreactivity demonstrated BimL-positive cells colocalized primarily with neurons. Scale bar, $8 \mu \mathrm{m}$. F, Western blot analyses of BimL in the cytosolic fraction and the mitochondrial fraction after $\mathrm{AFCl}$. BimL was present in the cytosolic fraction from the nonischemic control brains $(\mathrm{C})$ and was significantly induced $6 \mathrm{hr}$ after reperfusion without alternations in its subcellular localization. Cytochrome oxidase (COX) was used as an internal control for the mitochondrial fraction. G, Western blot analysis of BimL in the ischemic MCA territory after intracerebroventricular injection of the vehicle (V) or SP600125, a selective JNK inhibitor. Six hours after tFCl, BimL was significantly increased in the vehicle-treated animals compared with the nonischemic control brains (C), but was inhibited by treatment with SP600125 in a dose-dependent manner. $H$, Statistical analysis showed a significant decrease in BimL immunoreactivity in the SP600125treated group $(1.0 \mathrm{mg} / \mathrm{kg})$ compared with the vehicle-treated group $(\mathrm{V})$ in the entire MCA territory on the ischemic side $(n=4$; $\left.{ }^{*} p<0.05\right)$. The statistically significant difference in BimL expression disappeared in the SP600125-treated group at a dose of 0.5 $\mathrm{mg} / \mathrm{kg}$, compared with the nonischemic control brains (C) $\left(n=4 ;{ }^{\#} p<0.05\right)$. Error bars represent mean \pm SD.

analyses showed that the kinetics of phospho-MKK4 almost paralleled those of JNK activity and phospho-JNK. These results strongly suggest that the JNK signaling pathway was activated during reperfusion after tFCI. Furthermore, treatment with SP600125 exhibited selectivity in its inhibition of JNK activity and attenuated ischemia-induced apoptosis in the core area of ischemia. Levine's procedure used by Kuan et al. (2003) resulted in histologically slower changes, as found in global cerebral ischemia. The difference in conditions in the ischemic stress may affect these inconsistent results. In addition, there was no protective profile of SP600125 on the infarct volume seen in the results 
A

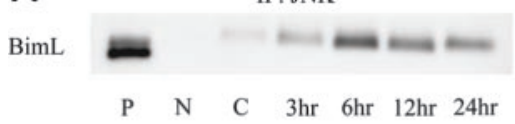

B

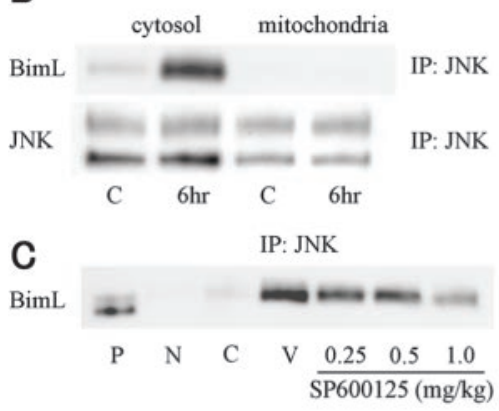

D

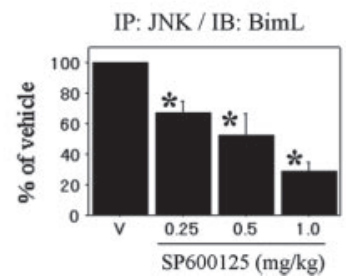

Figure 4. A, JNK immunoprecipitates (IP) were analyzed by Western blotting with an anti-BimL antibody in the whole-cell fraction from the ischemic MCA territory. BimL was increasingly coimmunoprecipitated with JNK after reperfusion, peaking at $6 \mathrm{hr}$. P, Positive control; N, negative control (absence of antibody); C, nonischemic control brain. B, Coimmunoprecipitation analyses for BimL in the cytosolic fraction and the mitochondrial fraction after $\mathrm{FCl}$. Interaction of JNK with BimL was observed in the cytosolic fraction, but not in the mitochondrial fraction, and was significantly increased $6 \mathrm{hr}$ after reperfusion compared with the nonischemic control brains (lane C). Equivalent levels of JNK in the nonischemic and ischemic brain samples (bottom). C, Coimmunoprecipitation analysis for BimL in the whole-cell fraction of the ischemic MCA territory with intracerebroventricular injection of the vehicle (lane V) or SP600125. Six hours after IFCI, JNK-BimL interaction was significantly increased in the vehicle-treated animals compared with the nonischemic control brains (lane C), but was inhibited by treatment with SP600125 in a dose-dependent manner. D, Quantitative analysis $(n=4)$ showed a significant reduction in JNK-BimL interaction in the SP600125-treated animals $6 \mathrm{hr}$ after $\mathrm{tFCl}$ compared with the vehicle-treated animals $(\mathrm{V})\left({ }^{*} p<0.05\right)$. IB, Immunoblot analysis. Error bars represent mean \pm SD. E, Representative photomicrographs show double immunofluorescent staining for phospho-JNK (p-JNK) and BimL. Six hours after reperfusion, p-JNK-positive cells were observed in the ischemic caudate-putamen. BimL immunoreactivity was also increased in the same view. Overlapped image of p-JNK and BimL immunoreactivity demonstrated p-JNK-positive cells colocalized with BimL immunoreactivity. Scale bar, $8 \mu \mathrm{m}$. F, Six hours after $\mathrm{tFCl}$, BimL expression in the whole-cell fraction immunoprecipitated by an antibody for Bax proteins significantly increased in the vehicle-treated animals (lane $6 \mathrm{hr}$ ) compared with the nonischemic control brains (lane C), and was significantly inhibited by SP600125 (SP) treatment (1.0 mg/kg).

A

\section{DLC1}

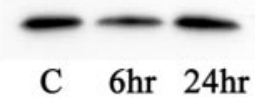

B

\section{DLC1}

\section{IP: BimL}

\section{C $6 \mathrm{hr} 24 \mathrm{hr}$}

\section{IP: DI}

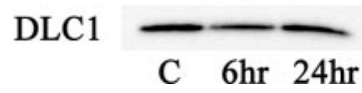

Figure 5. A, Western blot analysis showed a band with a molecular mass of $8 \mathrm{kDa}$ as DLC1 immunoreactivity in the whole-cell fraction. The level of DLC1 was transiently decreased $6 \mathrm{hr}$ after $\mathrm{tFCl}$. B, Decreased expression of DLC1 was indicated in both BimL and DI immunoprecipitates (IP) from the whole-cell fraction after $6 \mathrm{hr}$ of reperfusion.

of our TTC staining. From all of these data together, we conclude that JNK activity plays an important role in neuronal apoptosis induced in ischemic brain tissue in vivo.

A small number of reports showed c-Jun phosphorylation selectively detected in CA1 subregion neurons after global isch- emia (Gillardon et al., 1999), in the ischemic core after tFCI (Herdegen et al., 1998), or in the peri-infarct area of the brains of rat pups after permanent focal ischemia (Borsello et al., 2003), which support the concept that activated JNK can phosphorylate c-Jun, a component of the transcription factor AP-1 (activator protein 1), and can induce cell death by activating gene transcription. However, there is some inconsistency in the temporospatial distribution of phospho-c-Jun and phospho-JNK expression (Ferrer et al., 2003; Zablocka et al., 2003). It has also been reported that an increase in phospho-c-Jun levels was detected after 5 min of global ischemia without an increase in phospho-JNK levels (Gillardon et al., 1999). In fact, c-Jun phosphorylation and its transcriptional activity can be regulated by calcium-calmodulin-dependent protein kinases and by cAMP-responsive elementbinding protein without activation of JNK signaling. Moreover, N-terminal residues $\mathrm{Ser}^{63}$ and $\mathrm{Ser}^{73}$, which have been the sites reported to receive exclusive regulation by JNK, are not inevitably required for c-Jun transcriptional activity (Cruzalegui et al., 1999; Mielke and Herdegen, 2000). These findings suggest c-Jun is likely to be one of the downstream candidates of JNK signaling in neuronal cell death after ischemic stress, but may be more responsible for necrosis elicited by a robust influx of calcium ions through NMDA receptors and other kinds of calcium channels. Interestingly, in our studies, increased JNK activity caused no changes in phospho-c-Jun ( $\mathrm{Ser}^{63}$ ) expression up to $24 \mathrm{hr}$ after reperfusion, although we detected necrotic cell death in the ischemic core with the use of TTC staining. It is possible that unknown molecules that regulate ischemia-mediated neuronal apoptosis and necrosis are involved apart from the c-Jun-activating pathway. Thus, we hypothesize that the activated JNK signaling pathway can involve other substrates such as downstream molecules that mediate apoptotic stimuli after cerebral ischemia. Recent studies showed that JNK promoted the release of cytochrome $c$ and Smac-direct inhibitor-of-apoptosis protein binding protein with low pI (DIABLO) during apoptosis (Tournier et al., 2000; Chauhan et al., 2003). Targeted gene disruption studies indicate that Bax and Bak are essential for JNK-dependent apoptosis of fibroblasts exposed to ultraviolet radiation, whereas Bax activation in fibroblasts exposed to stress requires JNK (Lei et al., 2002). Moreover, we reported the release of cytochrome $c$ and Smac-DIABLO in the ischemic brain, which resulted in caspase activation (Sugawara et al., 1999; Saito et al., 2003). In turn, inhibitory effects on these mitochondria-derived proteins attenuated apoptotic cell death after in vivo global and focal cerebral ischemia (Chan et al., 1998; Chen et al., 1998; Namura et al., 1998). From these findings and our current results, we conclude that JNK activation may contribute to apoptosis in ischemic neurons by engaging the mitochondrial pathway. With this study, we established that Bax translocation is induced after cerebral ischemia, and 
although not complete, is significantly blocked by the inhibition of JNK activity. Other regulatory mechanisms for Bax expression can affect the results of its translocation on Western blot analysis, including the effect of SP600125 on the transcriptional and posttranslational controls. These results provide additional evidence for the role of JNK in the mitochondrial apoptotic pathway. However, the mechanism by which the JNK signaling cascade causes activation of Bax, one of the mitochondrial apoptogenic molecules, remains to be elucidated.

Bim is reportedly upregulated by the JNK pathway both at the transcriptional and posttranslational levels (Harris and Johnson, 2001; Puthalakath and Strasser, 2002; Putcha et al., 2003). In our studies, ischemic insults significantly induced BimL parallel to JNK activity. Moreover, SP600125, a selective JNK inhibitor, was significantly associated with the prevention of BimL induction. It is likely that BimL is transcriptionally upregulated in neurons via unknown mechanisms that are significantly linked to JNK activity, consistent with a previous report (Putcha et al., 2001). There are two major mechanisms regulating Bim posttranslationally: unleashing and phosphorylation. Under normal conditions, Bim is sequestered by binding to the microtubule-associated dynein motor complex through interaction with DLC1. Specific apoptotic stimuli in vitro unleash Bim alone from DLC1 or together with DLC1 from DI (Puthalakath et al., 1999; Puthalakath and Strasser, 2002; Lei and Davis, 2003). However, the role of DLC1 in Bim regulation in neurons is still unclear. In our current study, we observed transient reduction of DLC1 expression at $6 \mathrm{hr}$, independent of JNK activity, which may have affected decreased binding properties of DLC1 to both BimL and DI. These results might indicate that the dissociation of BimL from the dynein motor complex participates, in part, in the mechanism underlying BimL regulation in cerebral ischemia. Bim is also regulated by phosphorylation. Our results strongly support this evidence. First, the kinetics of JNK activation are very consistent with those of BimL phosphorylation. Second, the JNK inhibitor decreased BimL phosphorylation in a dose-dependent manner. Third, coimmunoprecipitation analysis demonstrated increased binding of BimL to JNK, whereas the dissociation of BimL from JNK was observed in the presence of SP600125. These data indicate that JNK likely involves BimL as a direct substrate for phosphorylation. It remains to be determined whether phosphorylation affects the proapoptotic activity of BimL. Our data are favorable for proapoptotic mechanisms enhanced by phosphorylation. First, BimL is phosphorylated during ischemic brain injury, with the same profile of kinetics as that of JNK activity. Second, the inhibition of BimL phosphorylation by SP600125 consistently attenuates BimL-Bax interaction and ischemia-induced apoptotic cell death. Furthermore, a previous report showed that SP600125 attenuated cell death of cerebellar granule neurons induced by overexpression of wild-type Bim, and that mutation of the Bim phosphorylation site induced less cell death (Putcha et al., 2003). Together, this information suggests that the phosphorylated forms of BimL increase cytotoxicity in neurons possibly through their increased affinity to Bax and the resultant Bax activation. There are still many issues to be addressed, including whether BimL overexpression itself promotes cell death or whether there are functions of phosphorylated BimL other than the enhancement of the proapoptotic ability. Moreover, the functional redundancy of $\mathrm{BH} 3$-only proteins and Bax during apoptosis has been reported (Putcha et al., 2003; Villunger et al., 2003), raising the possibilities that Bax is not the only substrate of BimL and that JNK-mediated apoptotic signaling can be conducted through unknown pathways other than BimL-Bax interaction.
The present study provides evidence for the role of the JNK signaling pathway in ischemia-induced neuronal apoptosis. We found ischemia-induced JNK activity and that its inhibition attenuated neuronal apoptosis. An antiapoptotic effect through JNK inhibition is partly mediated by prevention of Bax translocation. It is likely that Bim, a BH3-only protein, is directly phosphorylated by JNK and transduces JNK-mediated apoptotic signaling to Bax after tFCI.

\section{References}

Bennett BL, Sasaki DT, Murray BW, O’Leary EC, Sakata ST, Xu W, Leisten JC, Motiwala A, Pierce S, Satoh Y, Bhagwat SS, Manning AM, Anderson DW (2001) SP600125, an anthrapyrazolone inhibitor of Jun N-terminal kinase. Proc Natl Acad Sci USA 98:13681-13686.

Borsello T, Clarke PGH, Hirt L, Vercelli A, Repici M, Schorderet DF, Bogousslavsky J, Bonny C (2003) A peptide inhibitor of c-Jun N-terminal kinase protects against excitotoxicity and cerebral ischemia. Nat Med 9:1180-1186.

Chan PH, Kawase M, Murakami K, Chen SF, Li Y, Calagui B, Reola L, Carlson E, Epstein CJ (1998) Overexpression of SOD1 in transgenic rats protects vulnerable neurons against ischemic damage after global cerebral ischemia and reperfusion. J Neurosci 18:8292-8299.

Chauhan D, Li G, Hideshima T, Podar K, Mitsiades C, Mitsiades N, Munshi N, Kharbanda S, Anderson KC (2003) JNK-dependent release of mitochondrial protein, Smac, during apoptosis in multiple myeloma (MM) cells. J Biol Chem 278:17593-17596.

Chen J, Nagayama T, Jin K, Stetler RA, Zhu RL, Graham SH, Simon RP (1998) Induction of caspase-3-like protease may mediate delayed neuronal death in the hippocampus after transient cerebral ischemia. J Neurosci 18:4914-4928.

Cheng EH-YA, Wei MC, Weiler S, Flavell RA, Mak TW, Lindsten T, Korsmeyer SJ (2001) BCL-2, BCL-X $\mathrm{L}_{\mathrm{L}}$ sequester BH3 domain-only molecules preventing BAX- and BAK-mediated mitochondrial apoptosis. Mol Cell 8:705-711.

Cruzalegui FH, Hardingham GE, Bading H (1999) c-Jun functions as a calcium-regulated transcriptional activator in the absence of JNK/SAPK1 activation. EMBO J 18:1335-1344.

Davis RJ (2000) Signal transduction by the JNK group of MAP kinases. Cell 103:239-252.

Donovan N, Becker EBE, Konishi Y, Bonni A (2002) JNK phosphorylation and activation of BAD couples the stress-activated signaling pathway to the cell death machinery. J Biol Chem 277:40944-40949.

Ferrer I, Friguls B, Dalfó E, Planas AM (2003) Early modifications in the expression of mitogen-activated protein kinase (MAPK/ERK), stressactivated kinases SAPK/JNK and p38, and their phosphorylated substrates following focal cerebral ischemia. Acta Neuropathol (Berl) 105:425-437.

Fujimura M, Morita-Fujimura Y, Murakami K, Kawase M, Chan PH (1998) Cytosolic redistribution of cytochrome $c$ after transient focal cerebral ischemia in rats. J Cereb Blood Flow Metab 18:1239-1247.

Fujimura M, Morita-Fujimura Y, Kawase M, Copin J-C, Calagui B, Epstein CJ, Chan PH (1999) Manganese superoxide dismutase mediates the early release of mitochondrial cytochrome $c$ and subsequent DNA fragmentation after permanent focal cerebral ischemia in mice. J Neurosci 19:3414-3422.

Gillardon F, Spranger M, Tiesler C, Hossmann K-A (1999) Expression of cell death-associated phospho-c-Jun and p53-activated gene 608 in hippocampal CA1 neurons following global ischemia. Brain Res Mol Brain Res 73:138-143.

Graham SH, Chen J (2001) Programmed cell death in cerebral ischemia. J Cereb Blood Flow Metab 21:99-109.

Harris CA, Johnson Jr EM (2001) BH3-only Bcl-2 family members are coordinately regulated by the JNK pathway and require Bax to induce apoptosis in neurons. J Biol Chem 276:37754-37760.

Herdegen T, Claret F-X, Kallunki T, Martin-Villalba A, Winter C, Hunter T, Karin M (1998) Lasting N-terminal phosphorylation of c-Jun and activation of c-Jun N-terminal kinases after neuronal injury. J Neurosci 18:5124-5135

Irving EA, Bamford M (2002) Role of mitogen- and stress-activated kinases in ischemic injury. J Cereb Blood Flow Metab 22:631-647.

Krajewski S, Mai JK, Krajewska M, Sikorska M, Mossakowski MJ, Reed JC 
(1995) Upregulation of Bax protein levels in neurons following cerebral ischemia. J Neurosci 15:6364-6376.

Kuan C-Y, Whitmarsh AJ, Yang DD, Liao G, Schloemer AJ, Dong C, Bao J, Banasiak KJ, Haddad GG, Flavell RA, Davis RJ, Rakic P (2003) A critical role of neural-specific JNK3 for ischemic apoptosis. Proc Natl Acad Sci USA 100:15184-15189.

Lei K, Davis RJ (2003) JNK phosphorylation of Bim-related members of the Bcl2 family induces Bax-dependent apoptosis. Proc Natl Acad Sci USA 100:2432-2437.

Lei K, Nimnual A, Zong W-X, Kennedy NJ, Flavell RA, Thompson CB, BarSagi D, Davis RJ (2002) The Bax subfamily of Bcl2-related proteins is essential for apoptotic signal transduction by c-Jun $\mathrm{NH}_{2}$-terminal kinase. Mol Cell Biol 22:4929-4942.

Mielke K, Herdegen T (2000) JNK and p38 stress kinases-degenerative effectors of signal-transduction-cascades in the nervous system. Prog Neurobiol 61:45-60.

Namura S, Zhu J, Fink K, Endres M, Srinivasan A, Tomaselli KJ, Yuan J, Moskowitz MA (1998) Activation and cleavage of caspase-3 in apoptosis induced by experimental cerebral ischemia. J Neurosci 18:3659-3668.

O’Reilly LA, Cullen L, Visvader J, Lindeman GJ, Print C, Bath ML, Huang DCS, Strasser A (2000) The proapoptotic BH3-only protein Bim is expressed in hematopoietic, epithelial, neuronal, and germ cells. Am J Pathol 157:449-461.

Putcha GV, Moulder KL, Golden JP, Bouillet P, Adams JA, Strasser A, Johnson Jr EM (2001) Induction of BIM, a proapoptotic BH3-only BCL-2 family member, is critical for neuronal apoptosis. Neuron 29:615-628.

Putcha GV, Le S, Frank S, Besirli CG, Clark K, Chu B, Alix S, Youle RJ, LaMarche A, Maroney AC, Johnson Jr EM (2003) JNK-mediated BIM phosphorylation potentiates BAX-dependent apoptosis. Neuron 38:899-914.

Puthalakath H, Strasser A (2002) Keeping killers on a tight leash: transcrip- tional and post-translational control of the pro-apoptotic activity of $\mathrm{BH} 3-$ only proteins. Cell Death Differ 9:505-512.

Puthalakath H, Huang DCS, O’Reilly LA, King SM, Strasser A (1999) The proapoptotic activity of the Bcl-2 family member Bim is regulated by interaction with the dynein motor complex. Mol Cell 3:287-296.

Saito A, Hayashi T, Okuno S, Ferrand-Drake M, Chan PH (2003) Interaction between XIAP and Smac/DIABLO in the mouse brain after transient focal cerebral ischemia. J Cereb Blood Flow Metab 23:1010-1019.

Springer JE, Azbill RD, Nottingham SA, Kennedy SE (2000) Calcineurinmediated BAD dephosphorylation activates the caspase- 3 apoptotic cascade in traumatic spinal cord injury. J Neurosci 20:7246-7251.

Sugawara T, Fujimura M, Morita-Fujimura Y, Kawase M, Chan PH (1999) Mitochondrial release of cytochrome $c$ corresponds to the selective vulnerability of hippocampal CA1 neurons in rats after transient global cerebral ischemia. J Neurosci 19:RC39(1-6).

Tournier C, Hess P, Yang DD, Xu J, Turner TK, Nimnual A, Bar-Sagi D, Jones SN, Flavell RA, Davis RJ (2000) Requirement of JNK for stress-induced activation of the cytochrome $c$-mediated death pathway. Science 288:870-874.

Villunger A, Scott C, Bouillet P, Strasser A (2003) Essential role for the $\mathrm{BH} 3$-only protein Bim but redundant roles for Bax, Bcl-2, and Bcl-w in the control of granulocyte survival. Blood 101:2393-2400.

Zablocka B, Duzniewska J, Zajac H, Domanska-Janik K (2003) Opposite reaction of ERK and JNK in ischemia vulnerable and resistant regions of hippocampus: involvement of mitochondria. Brain Res Mol Brain Res 110:245-252.

Zong W-X, Lindsten T, Ross AJ, MacGregor GR, Thompson CB (2001) $\mathrm{BH} 3$-only proteins that bind pro-survival $\mathrm{Bcl}-2$ family members fail to induce apoptosis in the absence of Bax and Bak. Genes Dev 15:1481-1486. 